\title{
The effects of a $\mathrm{Ca}^{2+}$ chelator and heavy-metal-ion chelators upon $\mathrm{Ca}^{2+}$ oscillations and activation at fertilization in mouse eggs suggest a role for repetitive $\mathrm{Ca}^{2+}$ increases
}

\author{
Yvonne LAWRENCE ${ }^{\star}$, Jean Pierre OZIL $\uparrow$ and Karl SWANN ${ }^{\star 1}$ \\ *Department of Anatomy and Developmental Biology, University College, Gower Street, London WC1E 6BT, U.K., and †INRA Unite de Biologie de la Fecondation, 78352 \\ Jouy en Josas, France
}

\begin{abstract}
During fertilization in mouse eggs, the sperm triggers a series of intracellular $\mathrm{Ca}^{2+}$ oscillations that lead to egg activation, as indicated by pronuclear formation. We show that $\mathrm{Ca}^{2+}$ oscillations in fertilized mouse eggs can be inhibited by addition of either the $\mathrm{Ca}^{2+}$ chelator 1,2-bis-(o-aminophenoxy)ethane- $N, N$, $N^{\prime}, N^{\prime}$-tetra-acetic acid acetoxymethyl ester (BAPTA-AM) or the heavy-metal-ion chelator $N, N, N^{\prime}, N^{\prime}$-tetrakis-(2-pyridylmethyl) ethylenediamine (TPEN) plus dithiothreitol (DTT). Both treatments inhibited $\mathrm{Ca}^{2+}$ oscillations, but they had different effects upon egg activation. Blocking $\mathrm{Ca}^{2+}$ oscillations with BAPTA$\mathrm{AM}$ after the occurrence of just two $\mathrm{Ca}^{2+}$ spikes resulted in most eggs forming pronuclei. However, we found that BAPTA-AMtreated fertilizing eggs showed a decreased rate of protein synthesis, which by itself can promote egg activation. In contrast,
\end{abstract}

blocking $\mathrm{Ca}^{2+}$ oscillations with TPEN plus DTT was accompanied by the inhibition of egg activation with no significant effect on protein synthesis. In eggs that were fertilized and then treated with TPEN plus DTT, there was a correlation between the number of $\mathrm{Ca}^{2+}$ spikes and the proportion of eggs that formed pronuclei, as well as between the number of $\mathrm{Ca}^{2+}$ spikes and the time taken for pronuclear formation and the first mitosis to occur. The addition of TPEN plus DTT did not block the generation of $\mathrm{Ca}^{2+}$ spikes or pronuclear formation when eggs were artificially stimulated by electroporation pulses. These data suggest that TPEN plus DTT inhibits pronuclear formation in fertilizing eggs via the inhibition of $\mathrm{Ca}^{2+}$ oscillations and that the number of $\mathrm{Ca}^{2+}$ spikes may regulate egg activation.

\section{INTRODUCTION}

Repetitive spikes, or oscillations, in the intracellular free $\mathrm{Ca}^{2+}$ concentration are known to occur in a variety of different cell types [1,2]. Such cytosolic $\mathrm{Ca}^{2+}$ oscillations can occur in response to hormones or to many other extracellular stimuli that lead to the generation of inositol 1,4,5-trisphosphate $\left(\operatorname{Ins} P_{3}\right)$. The precise function of oscillations in $\mathrm{Ca}^{2+}$, as opposed to a monotonic rise in $\mathrm{Ca}^{2+}$, is not entirely clear [1,2]. However, it has been suggested that cellular responses may be modulated by the frequency, or the number, of $\mathrm{Ca}^{2+}$ oscillations [2,3]. One of the first examples of cytosolic $\mathrm{Ca}^{2+}$ oscillations to be described was that associated with fertilization in mouse eggs $[4,5]$. These $\mathrm{Ca}^{2+}$ oscillations last for several hours after sperm-egg interaction [5-7]. They appear to stop around the time of the formation of pronuclei, which occurs 4-6 h after sperm penetration and is one of the first visible indicators of egg activation in mammals $[6,8] . \mathrm{Ca}^{2+}$ oscillations similar to those in mouse eggs have now been described at fertilization in a number of different mammalian, and some nonmammalian, species $[7,9,10]$.

The mechanisms that lead to the generation of changes in $\mathrm{Ca}^{2+}$ concentration at fertilization are not fully understood [7,11]. Nevertheless it is clear that some form of increase in $\mathrm{Ca}^{2+}$ at fertilization is essential for egg activation in the mouse. Preloading eggs before fertilization with the $\mathrm{Ca}^{2+}$ chelator 1,2-bis- $(o-$ aminophenoxy)ethane- $N, N, N^{\prime}, N^{\prime}$-tetra-acetic acid (BAPTA) to block all $\mathrm{Ca}^{2+}$ oscillations prevents meiotic resumption and pronuclear formation after sperm entry [12]. In addition, it is known that increasing the $\mathrm{Ca}^{2+}$ concentration within mammalian eggs can lead to the activation of development [7,13,14]. Such parthenogenetic egg activation can be achieved by agents that cause either a single prolonged [13-15], or an oscillatory [12-17], $\mathrm{Ca}^{2+}$ increase. Previous work has shown that parthenogenetically stimulated mouse eggs can respond differently to different patterns of $\mathrm{Ca}^{2+}$ spikes that are imposed artificially by a series of electroporation pulses [16,17]. However, it is not known if the fertilized mouse egg also responds differentially to the different patterns of $\mathrm{Ca}^{2+}$ oscillations generated by the sperm. It is also uncertain whether the initial $\mathrm{Ca}^{2+}$ increase at fertilization is sufficient to lead to pronuclear formation and cell-cycle progression $[7,11,15]$. These question are difficult to answer, because one needs to inhibit $\mathrm{Ca}^{2+}$ oscillations at fertilization in a way that selectively allows different numbers of $\mathrm{Ca}^{2+}$ spikes to occur.

In the present study we have inhibited $\mathrm{Ca}^{2+}$ oscillations at fertilization by applying the $\mathrm{Ca}^{2+}$ chelator BAPTA, which was introduced into eggs in the acetoxymethyl ester (AM) form. In contrast with previous studies, where BAPTA was introduced before fertilization, we added BAPTA-AM after $\mathrm{Ca}^{2+}$ oscillations had been initiated by the sperm. This was done in order to investigate the effects of different numbers of $\mathrm{Ca}^{2+}$ spikes on egg activation. In the course of studying the effects of different ion chelators upon $\mathrm{Ca}^{2+}$ spikes in eggs, we discovered that some heavy-metal-ion chelators also inhibited other $\mathrm{Ca}^{2+}$ changes at fertilization. In particular, the membrane-permeable heavy-

Abbreviations used: BAPTA, 1,2-bis-(o-aminophenoxy)ethane- $N, N, N^{\prime}, N^{\prime}$-tetra-acetic acid; AM, acetoxymethyl ester; TPEN, $N, N, N^{\prime}, N^{\prime}$-tetrakis-(2pyridylmethyl)ethylenediamine; DTT, dithiothreitol; Ins $P_{3}$, inositol 1,4,5-trisphosphate; EF, electrical field.

1 To whom correspondence should be addressed (e-mail k.swann@ucl.ac.uk). 
metal-ion chelator $N, N, N^{\prime}, N^{\prime}$-tetrakis-(2-pyridylmethyl)ethylenediamine (TPEN) [18] inhibited $\mathrm{Ca}^{2+}$ oscillations at fertilization in mouse eggs. Such an inhibitory effect in mouse eggs is consistent with the finding that TPEN can inhibit hormoneinduced $\mathrm{Ca}^{2+}$ increases in pancreatic acinar cells [19]. In the present study we have compared the inhibitory effects of TPEN, combined with a reducing agent, with those of the membranepermeable $\mathrm{Ca}^{2+}$ chelator BAPTA-AM. Despite the fact that the two different treatments both inhibited $\mathrm{Ca}^{2+}$ oscillations, our data show that there are different consequences for mouse egg activation. These differences may be explained by an effect of BAPTA loading on protein synthesis [20]. We discuss the differential effects of TPEN and reducing agents upon egg activation in the context of the role of repetitive $\mathrm{Ca}^{2+}$ spikes at fertilization in mammals.

\section{MATERIALS AND METHODS}

\section{Media and reagents}

Experiments on mouse eggs were carried out in M2 medium (Hepes-buffered) supplemented with $4 \mathrm{mg} / \mathrm{ml}$ BSA (crystalline; ICN) [14]. To capacitate sperm, a T6 medium supplemented with $15 \mathrm{mg} / \mathrm{ml} \mathrm{BSA} \mathrm{(fraction} \mathrm{V;} \mathrm{Sigma)} \mathrm{was} \mathrm{used} \mathrm{[21].} \mathrm{The} \mathrm{chemicals}$ TPEN, dithiothreitol (DTT), 1,10-phenanthroline and desferroxamine were purchased from Sigma. BAPTA-AM was from Novabiochem. TPEN, BAPTA-AM, phenanthroline and desferroxamine were made up as stock solutions in DMSO and diluted into M2 medium for experiments. The final concentration of DMSO was less than $0.5 \%$. DTT was dissolved in M2 medium on the day of use.

\section{Preparation and handling of gametes}

Female MF1 mice were superovulated and eggs were collected 15-17 h after injection of human chorionic gonadotropin, as described previously [14,22]. The eggs were maintained in $200 \mu 1$ drops of M2 medium under light liquid paraffin at $37^{\circ} \mathrm{C}$. Just before each experiment, the zonae pellucidae were removed by brief treatment with acid Tyrode solution $(\mathrm{pH} 2.5)$ and the eggs were then washed several times in M2 medium. Sperm from CBA male mice were capacitated in T6 medium in a humidified $5 \%$ $\mathrm{CO}_{2}$ incubator at $37^{\circ} \mathrm{C}$ [21]. Sperm were added to eggs after at least $2 \mathrm{~h}$ of capacitation. The activation of eggs was assessed by observing gametes to check for either second polar body or pronuclear formation. The female pronucleus was discriminated from the male pronucleus because it is smaller in size and usually forms in close proximity to the second polar body. The activation stages of eggs were scored towards the end of experiments $(>$ $6 \mathrm{~h}$ ), and eggs were regarded as fully activated when the normal complement of two pronuclei was observed.

\section{Measurement of $\mathrm{Ca}^{2+}$ changes in eggs}

Intracellular $\mathrm{Ca}^{2+}$ changes were measured with the AM derivatives of fura red (Molecular Probes) or indo-1 (Molecular Probes). Fura red-AM and indo-1-AM were made up as $2 \mathrm{mM}$ stocks in DMSO plus $5 \%$ Pluronic F127 (Molecular Probes), which were diluted 1000-fold into M2 medium to form the loading buffer. The loading medium was also supplemented with $250 \mu \mathrm{M}$ of the anion-exchange inhibitor sulfinpyrazone (ICN), which helps to prevent compartmentalization and extrusion of the dye [23]. Sulfinpyrazone did not affect the frequency of $\mathrm{Ca}^{2+}$ spikes or the timing of pronuclear formation in fertilized eggs (Y. Lawrence and K. Swann, unpublished work). Eggs were incubated for $10-12 \mathrm{~min}$ in $2 \mu \mathrm{M}$ fura red-AM or indo-1-AM before being placed in the chamber on the microscope stage. For $\mathrm{Ca}^{2+}$ measurements in fertilizing eggs, these were placed in a $1 \mathrm{ml}$ bath of medium that was heated to $37^{\circ} \mathrm{C}$ and covered with mineral oil to prevent evaporation. Eggs adhered to a polylysine-coated coverslip that formed the base of the bath. Fertilization was initiated by adding $50 \mu \mathrm{l}$ drops of the capacitated sperm preparation into the bath containing the eggs.

For fertilization experiments, the $\mathrm{Ca}^{2+}$ concentration was monitored by measuring the fluorescence from individual eggs loaded with fura red-AM. The microscope used was a Nikon Diaphot 200 equipped with epifluorescence optics and either a $\times 20,0.75$ numerical aperture or a $\times 40,0.8$ numerical aperture objective lens to view and excite the oocytes. A $100 \mathrm{~W}$ Xenon lamp was the source of excitation light that was filtered by neutral-density filters and the $10 \mathrm{~nm}$ bandpass filters. A cooled CCD camera was used to measure emitted light. The excitation filters, camera shutter and data collection were controlled by a computer using the Newcastle Photometrics Multipoint System (Newcastle upon Tyne, U.K.). This system allowed for simultaneous recording from up to 16 eggs. For fura red-AM-loaded egg, the excitation wavelength was altered from $440 \mathrm{~nm}$ to $490 \mathrm{~nm}$ and the emitted fluorescent light was measured through a $590 \mathrm{~nm}$ longpass filter [24]. Recordings are presented as fluorescence ratios against time because of uncertainties about the calibration of dye in the cytoplasm [24].

\section{Assay of protein synthesis}

Protein synthetic activity was assayed as described previously [25]. Briefly, zona-intact mouse eggs were fertilized and then, after $1 \mathrm{~h}$, groups of 20 eggs were exposed to TPEN plus DTT or to BAPTA-AM for $1 \mathrm{~h}$ while being incubated in M2 medium containing L-[4,5- $\left.{ }^{3} \mathrm{H}\right]$ leucine $(50 \mu \mathrm{Ci} / \mathrm{ml}$; Amersham). After incubation the eggs were washed three times in M2 containing unlabelled leucine before lysis by freeze/thaw cycles. BSA was added to the samples as carrier, and proteins were precipitated and washed with trichloroacetic acid and then dissolved overnight in $1 \mathrm{M} \mathrm{NaOH}$ before transfer into Optiphase scintillation fluid (Wallac) to count radioactivity. Background radioactivity was obtained from the final trichloroacetic acid wash. We verified that incubation of eggs under these conditions with $10 \mu \mathrm{M}$ of the protein synthesis inhibitor cycloheximide led to $>95 \%$ inhibition of incorporation of $\left[4,5-{ }^{3} \mathrm{H}\right] \mathrm{leucine}[25,26]$.

\section{Electrical field (EF) pulse-induced egg activation protocols}

Mouse eggs previously loaded with indo-1-AM were set up for $\mathrm{Ca}^{2+}$ measurements during EF pulse stimulation. Individual eggs were held by a suction pipette between two platinum electrodes in a perfusion chamber containing M2 medium maintained at $37^{\circ} \mathrm{C}$ and placed on the stage of an inverted microscope [17,27]. An EF radio-frequency pulse of $1.5 \mathrm{kV} / 10 \mathrm{kHz}$ lasting for $300 \mu \mathrm{s}$ was applied at 10 min intervals, and the intracellular $\mathrm{Ca}^{2+}$ changes were measured and recorded using a Newcastle Photometrics System. At $10 \mathrm{~s}$ before each EF stimulation, the medium was rapidly exchanged with a glucose solution $(0.3 \mathrm{M})$ containing $100 \mu \mathrm{M} \mathrm{Ca}^{2+}$. At the end of each EF pulse the glucose solution was rapidly exchanged for M2 medium. The use of a rapid perfusion system facilitates the decrease in $\mathrm{Ca}^{2+}$ concentration after an EF pulse, and is particularly necessary during repetitive pulse stimulation. Five recordings were performed for each treatment, and the average $\mathrm{Ca}^{2+}$ changes were computed and charted using SIGMA plot software 3.2.

A large chamber was used to study the time course of pronuclear formation in groups of eggs following treatment with TPEN and DTT. The protocols for perfusion and EF stimulation in these activation experiments were identical to those used in 
corresponding $\mathrm{Ca}^{2+}$ measurements, i.e. one EF pulse every 10 min for $4 \mathrm{~h}$. The time course of pronuclear formation after treatment was monitored visually using an inverted microscope equipped with Nomarski optics as described elsewhere [16,17].

\section{RESULTS}

\section{Inhibition of $\mathrm{Ca}^{2+}$ oscillations in fertilizing eggs}

Figure 1(A) shows a typical series of $\mathrm{Ca}^{2+}$ oscillations, as monitored by fura red fluorescence, after in vitro fertilization in a mouse egg. In 47 fertilized eggs, a mean $( \pm$ S.D.) of $15.8 \pm 8.6$ $\mathrm{Ca}^{2+}$ spikes occurred at an interval of $15.1 \pm 8.6 \mathrm{~min}$. This pattern of $\mathrm{Ca}^{2+}$ oscillation is similar to that reported with other fluorescent dye indicators in fertilizing mouse eggs $[7,12,28]$. In order to examine the effects of different numbers of $\mathrm{Ca}^{2+}$ spikes upon egg activation, we sought means of rapidly inhibiting $\mathrm{Ca}^{2+}$ oscillations after they had been initiated by sperm. One method for inhibiting $\mathrm{Ca}^{2+}$ oscillations in mature eggs and immature oocytes is to add BAPTA-AM. Figure 1(B) shows that addition of the membrane-permeable $\mathrm{Ca}^{2+}$ chelator BAPTA-AM after the start of $\mathrm{Ca}^{2+}$ oscillations effectively inhibited $\mathrm{Ca}^{2+}$ spikes. Such inhibition was seen in most eggs at $5 \mu \mathrm{M}$ BAPTA-AM and in all eggs when the chelator was used at concentrations of $10-20 \mu \mathrm{M}$ (Table 1).

The use of BAPTA-AM provided one means of rapidly inhibiting $\mathrm{Ca}^{2+}$ oscillations. Another method of inhibiting $\mathrm{Ca}^{2+}$ oscillations in mouse eggs made use of a fortuitous novel finding. Some of the dyes used to monitor $\mathrm{Ca}^{2+}$ can be affected by heavymetal ions [18]. In the course of testing for a contribution of heavy-metal ions to fluorescence signals in mouse eggs, we found that the membrane-permeable chelator TPEN inhibited $\mathrm{Ca}^{2+}$ spikes. Figure $1(\mathrm{C})$ shows that the addition of $40 \mu \mathrm{M}$ TPEN to
Table 1 Effects of different metal-ion chelators on $\mathrm{Ca}^{2+}$ oscillations and activation of oocytes

\begin{tabular}{lccc}
\hline & & $\begin{array}{l}\text { Eggs in which } \mathrm{Ca}^{2+} \\
\text { spikes stopped }(\%)\end{array}$ & $\begin{array}{l}\text { Activation } \\
\text { (pronuclear formation) (\%) }\end{array}$ \\
\hline [Chelator] $(\mu \mathrm{M})$ & No. of eggs & \\
\hline $\begin{array}{l}\text { BAPTA-AM } \\
5\end{array}$ & & & 94 \\
10 & 96 & 97 & 100 \\
20 & 32 & 100 & 100 \\
TPEN & 30 & 100 & \\
10 & & & 80 \\
20 & 14 & 29 & 72 \\
40 & 16 & 40 & 66 \\
40 (+1 mM DTT) & 242 & 70 & 71 \\
Phenanthroline & & 92 & \\
10 & 31 & 81 & 46 \\
20 & 16 & 100 & $51^{\star}$ \\
40 & 15 & 100 & $0^{*}$
\end{tabular}

* Egg lysis occurred in non-activated eggs.

mouse eggs was effective in inhibiting $\mathrm{Ca}^{2+}$ oscillations after they had been initiated by sperm-egg interaction. We also found that phenanthroline was effective at inhibiting $\mathrm{Ca}^{2+}$ oscillations in eggs. However, unlike TPEN, phenanthroline caused a slow elevation of $\mathrm{Ca}^{2+}$ levels, and lysis occurred within a few hours of application (Table 1). Since TPEN did not cause any progressive elevation of $\mathrm{Ca}^{2+}$ levels, nor any signs of cell lysis, further experiments were restricted to investigations of TPEN.

The addition of TPEN to fertilizing eggs was not as effective at inhibiting $\mathrm{Ca}^{2+}$ oscillations as was addition of $5-20 \mu \mathrm{M}$
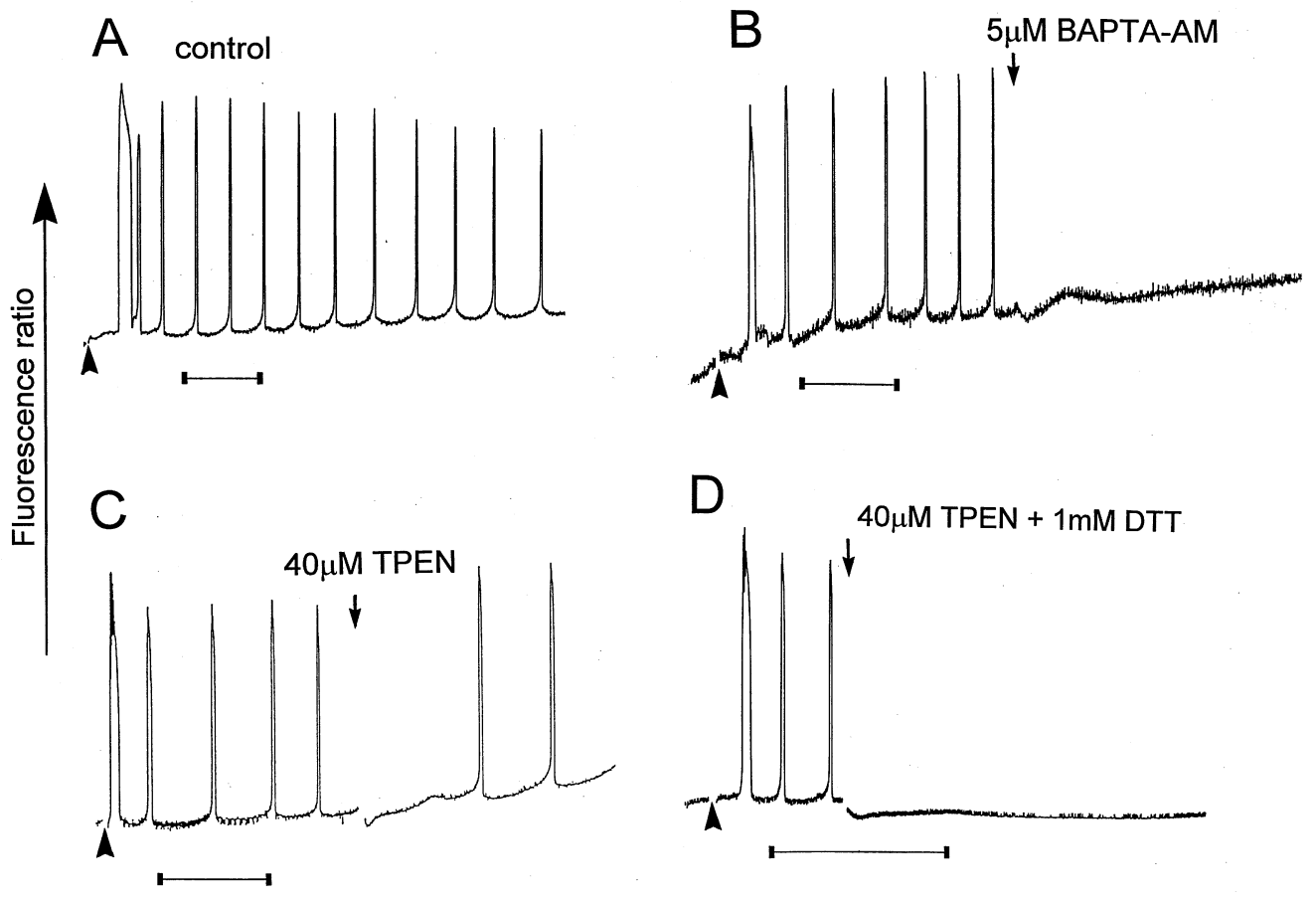

Figure 1 Addition of membrane-permeable metal-ion chelators after the start of $\mathrm{Ca}^{2+}$ oscillations in fertilizing mouse eggs

$\mathrm{Ca}^{2+}$ was monitored with fura red-AM. (A) Typical response in a control fertilized egg; (B) addition of $5 \mu \mathrm{M}$ BAPTA-AM inhibited $\mathrm{Ca}^{2+}$ oscillations; (C) $40 \mu \mathrm{M}$ TPEN reduced the frequency of $\mathrm{Ca}^{2+}$ oscillations; (D) $\mathrm{Ca}^{2+}$ oscillations were blocked by the simultaneous addition of TPEN $(40 \mu \mathrm{M})$ and DTT (1 mM). The time bars indicate 30 min. 
A

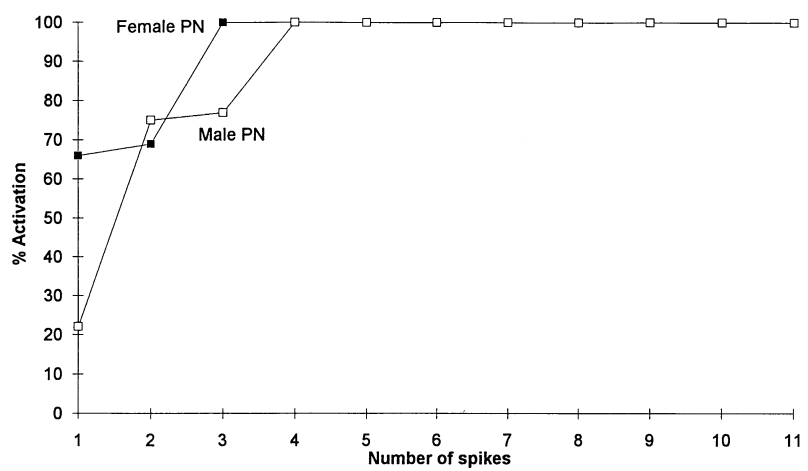

B

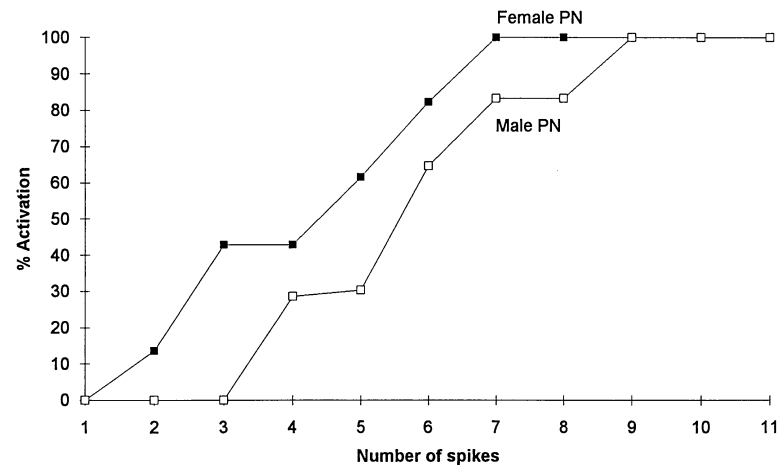

Figure 2 Relationship between the percentage of mouse eggs forming male and female pronculei and the number of $\mathrm{Ca}^{2+}$ spikes that they had undergone before addition of (A) BAPTA-AM or (B) TPEN plus DTT

Mouse eggs in which the number of $\mathrm{Ca}^{2+}$ oscillations had been measured were treated with BAPTA-AM or TPEN plus DTT for $1 \mathrm{~h}$ as in Figure 1, and were scored for pronuclei (PN). Data are plotted for eggs in which oscillations were completely blocked by the addition of drugs. The percentage activation is calculated from the number of eggs that formed either a female or a male ( $\square$ ) pronucleus. These curves were compiled using data from 85 eggs for $(\mathbf{A})$ and 242 eggs for $(\mathbf{B})$.

BAPTA-AM. However, it proved possible to increase the efficiency of inhibition by TPEN by adding a thiol reducing agent. There were two reasons for initially examining the effects of thiol reagents upon $\mathrm{Ca}^{2+}$ oscillations in mouse eggs. Firstly, it has been shown that the thiol reducing agent DTT can enhance the frequency of $\mathrm{Ca}^{2+}$ oscillations in fertilizing eggs [28]. Thiol reagents can also either enhance or inhibit the ability of heavymetal ions to trigger $\mathrm{Ca}^{2+}$ release from intracellular stores in muscle [29]. We confirmed that DTT increased the frequency of oscillations at fertilization (results not shown). However, rather than stimulating oscillations, Figure 1(D) and Table 1 indicate that the addition of DTT along with TPEN to fertilized eggs enhanced the ability of TPEN to inhibit $\mathrm{Ca}^{2+}$ oscillations. The combination of TPEN and DTT proved almost as effective as BAPTA-AM in blocking the sperm-induced $\mathrm{Ca}^{2+}$ oscillations (Table 1). Since both treatments rapidly inhibited $\mathrm{Ca}^{2+}$ oscillations, further studies on fertilizing mouse eggs were restricted to comparing the effects of TPEN plus DTT with those of BAPTAAM.

\section{Egg activation after inhibition of $\mathrm{Ca}^{2+}$ oscillations}

The $\mathrm{Ca}^{2+}$ oscillations seen at fertilization are responsible for activating the mammalian egg [7,12]. The initial signs of egg activation consist of the extrusion of the second polar body, with full activation being indicated by the formation of both female and male pronuclei [8]. The activation of eggs was assessed 4-6 h after fertilized eggs had been treated with either BAPTA-AM or TPEN plus DTT. Eggs were exposed to either of these inhibitory treatments for $1 \mathrm{~h}$ before they were washed out; the activation data in Table 1 were compiled from eggs in which $\mathrm{Ca}^{2+}$ was monitored. There was a clear difference in the activation rates obtained with BAPTA-AM and TPEN plus DTT. We found that nearly all the eggs that had been treated with BAPTA-AM after $\mathrm{Ca}^{2+}$ transients had been initiated formed both female and male pronuclei. In contrast, a proportion of the eggs that were exposed in a similar way to TPEN plus DTT did not form pronuclei.

The different effects of BAPTA-AM and TPEN plus DTT upon egg activation are illustrated in Figure 2, which again shows data from eggs that were treated with these agents after $\mathrm{Ca}^{2+}$ spikes had been initiated by sperm. Figure 2 shows the percentage of eggs that were activated, as judged by the formation of male and female pronuclei, against the number of $\mathrm{Ca}^{2+}$ spikes that an egg had undergone before addition of agents that blocked $\mathrm{Ca}^{2+}$ oscillations. All eggs that showed at least one $\mathrm{Ca}^{2+}$ transient, before application of either inhibitor, underwent second polar body extrusion. For both treatments there was also a correlation between the number of $\mathrm{Ca}^{2+}$ spikes that occurred in eggs and the activation rate, as judged by pronuclear formation. In particular, more $\mathrm{Ca}^{2+}$ spikes were associated with a greater pronuclear formation rate. However, there were differences in the number of $\mathrm{Ca}^{2+}$ spikes associated with pronuclear formation that depended upon the inhibitor used. Figure 2(A) shows that most eggs treated with BAPTA-AM formed both pronuclei after the occurrence of two $\mathrm{Ca}^{2+}$ spikes, and the occurrence of four $\mathrm{Ca}^{2+}$ spikes was always accompanied by complete egg activation (the formation of both pronuclei). In contrast, when eggs had undergone between one and four $\mathrm{Ca}^{2+}$ spikes before treatment with TPEN plus DTT, the majority did not form either pronucleus. When more $\mathrm{Ca}^{2+}$ spikes had occurred in the TPEN+ DTT-treated eggs, there was an increase in the percentage of eggs forming pronuclei. Eggs that had undergone nine or more $\mathrm{Ca}^{2+}$ spikes before addition of TPEN + DTT all formed two pronuclei (Figure 2B). Both of these sets of data suggest that egg activation at fertilization is correlated with the number of $\mathrm{Ca}^{2+}$ spikes that have occurred in eggs. However, there are differences in the number of $\mathrm{Ca}^{2+}$ spikes that is correlated with formation of pronuclei, depending upon the inhibitor used.

In addition to the correlation between the number of $\mathrm{Ca}^{2+}$ spikes and the percentage pronuclear formation, we also found correlations with the timing of events in the first cell cycle. Figure 3(A) shows the time taken for the formation of pronuclei in different groups of eggs that displayed two particularly common values (10 and 21) for the number of $\mathrm{Ca}^{2+}$ spikes before the addition of TPEN plus DTT. We also looked at the formation of pronuclei in control (not treated with TPEN, DTT or BAPTAAM) eggs that underwent either 10 or $21 \mathrm{Ca}^{2+}$ spikes before spontaneously stopping oscillations. Figure 3(A) shows that there was a significant difference in the time taken to form pronuclei in these two groups of eggs, such that the greater number of $\mathrm{Ca}^{2+}$ spikes was associated with a more rapid rate of pronuclear formation. These differences in timing of events also extended into the first mitosis. Figure 3(B) shows that the time taken to undergo nuclear envelope breakdown during entry into mitosis was significantly shorter for the eggs that displayed 21 

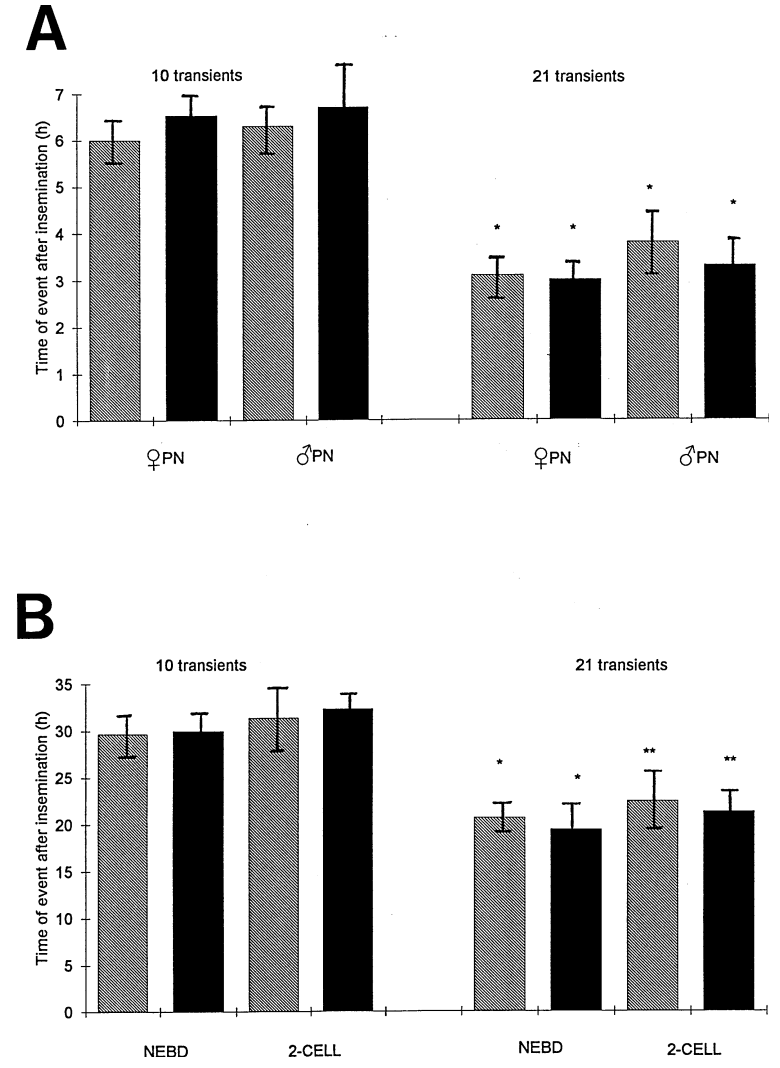

Figure 3 Rates of activation in mouse eggs that generated 10 transients and those that generated 21 transients

The eggs that were treated with TPEN plus DTT and generated either 10 or 21 transients are represented by the solid bars. Control eggs that generated either 10 or 21 transients are represented by hatched bars. (A) The time taken for male and female pronucleus (PN) formation is indicated for the four different groups of eggs. (B) The time taken for nuclear envelope breakdown (NEBD) and cleavage to the two-cell stage is shown for each of the four groups of eggs. Data are from 14 control eggs that generated 10 transients, 14 control eggs that generated 21 transients, 15 TPEN + DTT-treated eggs that generated 10 transients, and 12 TPEN + DTTtreated eggs that generated 21 transients. Significance of differences compared with eggs generating 10 transients: ${ }^{*} P<0.05 ;{ }^{* \star} P<0.001$ (Student's $t$-test).

$\mathrm{Ca}^{2+}$ spikes than for those that displayed 10 spikes. The time to cleavage to the two-cell stage was also shorter for eggs with the greater number of $\mathrm{Ca}^{2+}$ spikes. These differences in timing of the events of pronuclear formation and the first mitosis existed in control eggs as well as in eggs that were exposed to TPEN plus DTT. These data suggest that there is a correlation between the number of $\mathrm{Ca}^{2+}$ spikes and the timing of activation and the first cell cycle after fertilization in the mouse.

\section{Effects of ion chelators on protein synthesis}

Our data suggest there are correlations between $\mathrm{Ca}^{2+}$ spikes and activation events. However, we saw differences in the number of $\mathrm{Ca}^{2+}$ spikes correlated with pronuclear formation, depending upon the agent used to inhibit $\mathrm{Ca}^{2+}$ oscillations. One possible reason for the different effects on egg activation of TPEN and BAPTA is the level of protein synthesis. It has been shown that BAPTA-AM loading can inhibit protein synthesis in somatic cells [20], and the inhibition of protein synthesis is known to enhance $\mathrm{Ca}^{2+}$-induced egg activation in mammals $[25,26]$. We investigated the effects of BAPTA-AM and TPEN plus DTT
Table 2 Comparison of the effects of BAPTA-AM and TPEN plus DTT on the incorporation of $L-\left[{ }^{3} \mathrm{H}\right]$ leucine into proteins in fertilized mouse eggs

Zona-intact mouse eggs were fertilized, and after $1 \mathrm{~h}$ the agents shown were added for a further $1 \mathrm{~h}$ period. Results are expressed as a percentage of the values obtained with control eggs that were fertilized on the same day, and are means \pm S.D. of six separate experiments.

\begin{tabular}{ll}
\hline Agents & L-[3H]Leucine incorporated $(\%)$ \\
\hline $40 \mu \mathrm{M}$ TPEN & $85.4 \pm 8.6$ \\
$40 \mu \mathrm{M}$ TPEN $+1 \mathrm{mM}$ DTT & $87.2 \pm 5.4$ \\
$10 \mu \mathrm{M}$ BAPTA-AM & $34.8 \pm 11.2$ \\
\hline
\end{tabular}

upon protein synthesis in fertilized mouse eggs under the same experimental conditions as were used to inhibit $\mathrm{Ca}^{2+}$ oscillations. Table 2 shows the rate of leucine incorporation into mouse eggs after fertilization. Compared with control eggs (fertilized but not exposed to any drugs), the eggs treated with BAPTA-AM showed a decrease in leucine incorporation. In contrast, the addition of TPEN alone, or TPEN in combination with DTT, did not have a great effect upon leucine incorporation. These data suggest that BAPTA-AM treatment inhibits protein synthesis in mouse eggs after fertilization. This dual action on $\mathrm{Ca}^{2+}$ oscillations and on protein synthesis suggests that the results of experiments using BAPTA to block $\mathrm{Ca}^{2+}$ oscillations may be more difficult to interpret than those obtained using TPEN and DTT.

\section{Effects of TPEN plus DTT on artificial activation}

Since addition of TPEN plus DTT to fertilizing eggs did not appear to affect protein synthesis, it is possible that the correlation between the number of $\mathrm{Ca}^{2+}$ spikes and the activation rate in Figure 2(B) represents a relationship between the pattern of $\mathrm{Ca}^{2+}$ oscillations and the degree of egg activation. However, before this conclusion can be made, it was important to establish that TPEN plus DTT did not affect any events downstream of $\mathrm{Ca}^{2+}$ spikes. This possibility was tested by examining the rate of pronuclear formation in eggs that were induced to undergo $\mathrm{Ca}^{2+}$ spikes despite the presence of TPEN and DTT. Previously we have shown that the pattern of $\mathrm{Ca}^{2+}$ spikes at fertilization can be mimicked by repeated application of electroporation pulses in the presence of $\mathrm{Ca}^{2+}$ [17]. Each electroporation pulse leads to an influx of $\mathrm{Ca}^{2+}$, and the series of repeated pulses mimics the way in which the sperm activates the egg, resulting in high rates of pronuclear formation [16,17]. Figure 4 shows the $\mathrm{Ca}^{2+}$ spikes initiated in unfertilized mouse eggs that were exposed to electroporation pulses. The pattern of $\mathrm{Ca}^{2+}$ spikes initiated by this artificial method was not altered when eggs were stimulated in the presence of TPEN and DTT (Figure 4). This indicates that TPEN plus DTT was not buffering $\mathrm{Ca}^{2+}$ in the egg, or affecting the recovery from $\mathrm{Ca}^{2+}$ increases.

We incubated eggs in TPEN plus DTT for $1 \mathrm{~h}$, exposed them to the pattern of pulses as in Figure 4, and then examined the formation of pronuclei. Table 3 shows the percentage pronuclear formation in electroporation-treated eggs in the presence and absence of TPEN plus DTT. Since these eggs are activated in the absence of sperm, the formation of a female pronucleus is the assay for egg activation. Table 3 indicates that the control and treated groups of eggs showed similar rates of egg activation. The time taken to form pronuclei was also similar. The period of exposure of eggs to TPEN plus DTT in these experiments was as long as in the fertilization experiments, and began at the very beginning of the activation protocol. These data 

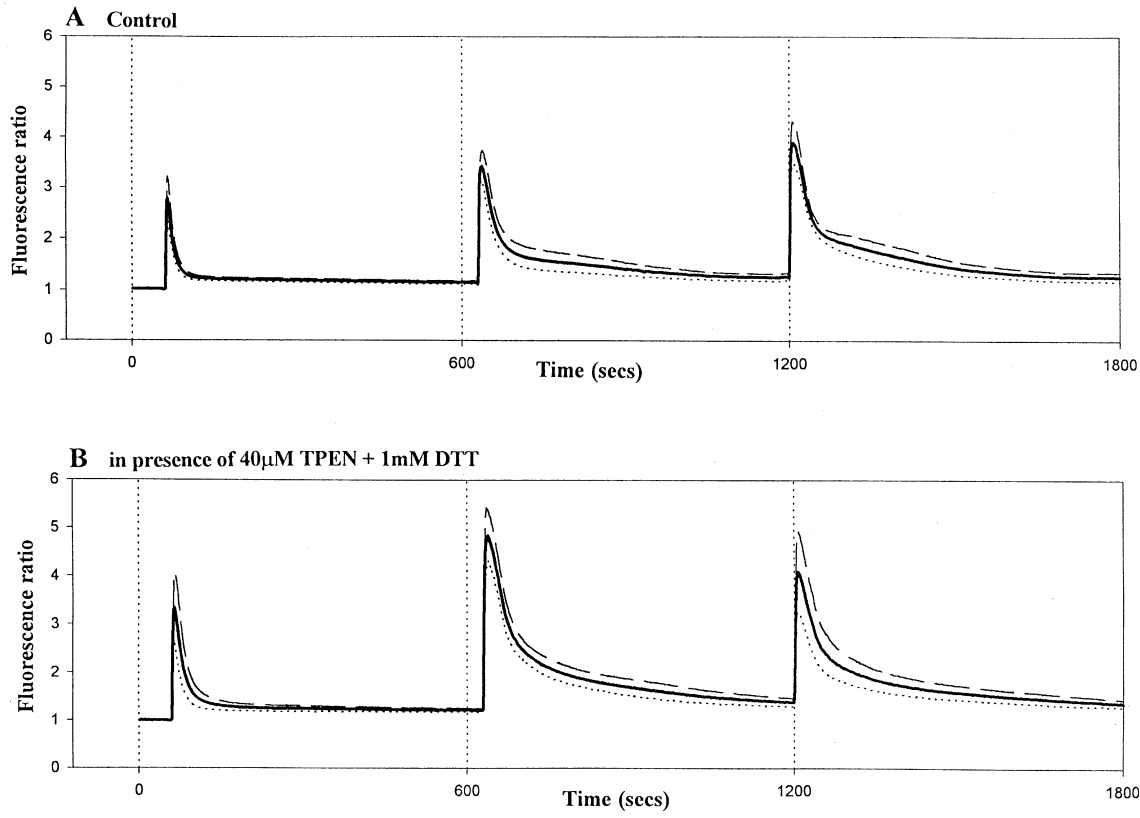

\section{Figure 4 EF pulse-induced increases in intracellular $\mathrm{Ca}^{2+}$ concentration $\left(\left[\mathrm{Ca}^{2+}\right]_{\mathrm{i}}\right)$ recorded with indo-1-AM}

(A) Typical control responses; (B) $\mathrm{Ca}^{2+}$ response after addition of $40 \mu \mathrm{M}$ TPEN plus $1 \mathrm{mM}$ DTT. The dotted and dashed lines indicate the full range of variability, by showing eggs that had the most different responses from a typical one (solid line).

Table 3 Rates of pronuclear formation in mouse eggs triggered by stimulation of EF pulse-induced $\mathrm{Ca}^{2+}$ oscillations

TPEN and DTT were used at concentrations of $40 \mu \mathrm{M}$ and $1 \mathrm{mM}$ respectively.

\begin{tabular}{|c|c|c|}
\hline \multirow[b]{2}{*}{$\begin{array}{l}\text { Time after start of } \\
\text { EF stimulation (h) }\end{array}$} & \multicolumn{2}{|c|}{ Pronuclear formation (\%) } \\
\hline & $\begin{array}{l}\text { Control eggs } \\
(n=53)\end{array}$ & $\begin{array}{l}\text { TPEN + DTT-treated eggs } \\
(n=65)\end{array}$ \\
\hline 4 & 19 & 22 \\
\hline 5 & 72 & 52 \\
\hline 6 & 88 & 78 \\
\hline 7 & 91 & 92 \\
\hline 8 & 91 & 94 \\
\hline
\end{tabular}

suggest that TPEN plus DTT does not have a significant effect upon events downstream of $\mathrm{Ca}^{2+}$ signals that lead to pronuclear formation, even when the agents are present from the very start of the activation process.

\section{DISCUSSION}

We show here that chelators of heavy-metal ions and a chelator of $\mathrm{Ca}^{2+}$ can inhibit $\mathrm{Ca}^{2+}$ oscillations after they have been initiated in mammalian eggs. However, the consequences of the inhibition of $\mathrm{Ca}^{2+}$ oscillations for egg activation, as defined by pronuclear formation, depend on the nature of the agent used to inhibit $\mathrm{Ca}^{2+}$ responses.

While it is expected that BAPTA will block $\mathrm{Ca}^{2+}$ oscillations due to its ability to chelate $\mathrm{Ca}^{2+}$, it is not clear why TPEN was able to inhibit $\mathrm{Ca}^{2+}$ oscillations in mouse eggs. At the concentrations that we used, TPEN would not be expected to chelate significant amounts of cytosolic $\mathrm{Ca}^{2+}[18,30]$. A lack of effect of
TPEN plus DTT on general $\mathrm{Ca}^{2+}$ buffering is also supported by the finding that the time course of electroporation-induced $\mathrm{Ca}^{2+}$ increases was unaltered by these agents. TPEN can also chelate $\mathrm{Ca}^{2+}$ inside the endoplasmic reticulum of cells, and this might offer one explanation for its actions in eggs [30], although higher concentrations $(>100 \mu \mathrm{M})$ chelated $\mathrm{Ca}^{2+}$ in the endoplasmic reticulum [30] than were used in the present studies. TPEN chelates a number of heavy-metal ions, including $\mathrm{Zn}, \mathrm{Fe}, \mathrm{Mn}$ and $\mathrm{Cu}$, more effectively than it chelates $\mathrm{Ca}^{2+}$ [18]. Chelation of $\mathrm{Fe}$ ions does not seem to be relevant, since the selective Fe chelator desferroxime was not effective at inhibiting $\mathrm{Ca}^{2+}$ oscillations (results not shown). An effect of TPEN on other heavy-metal ions, such as $\mathrm{Zn}, \mathrm{Fe}$ or $\mathrm{Mn}$, is a possible explanation, because we found that $\mathrm{Ca}^{2+}$ oscillations could also be inhibited by another membrane-permeable heavy-metal-ion chelator, phenathroline [31]. Phenanthroline was clearly toxic to eggs and was not used in our studies. However, TPEN caused no visible damage to eggs, did not affect protein synthesis, and did not inhibit events leading to pronuclear formation in parthenogenetically stimulated eggs. If the inhibitory effect of TPEN is explained by chelation of another heavy-metal ion, then the effects may not be specific to fertilization, since it has been shown that TPEN inhibits $\mathrm{Ca}^{2+}$ increases generated by low doses of cholecystokinin in pancreatic acinar cells [19]. Such low concentrations of cholecystokinin can trigger large-amplitude $\mathrm{Ca}^{2+}$ oscillations that are similar in form to those seen in fertilizing mammalian eggs $[5,7,12,28,32]$.

It is also possible that the effects of TPEN are related to the findings that heavy-metal ions can trigger $\mathrm{Ca}^{2+}$ release in muscle and other cell types [29]. We have also found that extracellular addition of some heavy metals such as $\mathrm{Cd}$ triggers large $\mathrm{Ca}^{2+}$ increases in mouse eggs (Y. Lawrence and K. Swann, unpublished work). These effects of heavy-metal ions are proposed to be on protein thiol groups [29]. Whether this has direct relevance to our finding that DTT enhanced the inhibitory effects of TPEN is 
unclear. Nevertheless, both $\operatorname{Ins} P_{3}$ and ryanodine receptor $\mathrm{Ca}^{2+}$ channels are present in mouse eggs, and they are known to possess critical thiol groups that are involved in effecting $\mathrm{Ca}^{2+}$ release $[1,29,33]$. It is possible that endogenous heavy-metal ions associated with these thiol groups can modulate $\mathrm{Ca}^{2+}$ release in mouse eggs.

Regardless of the precise mechanism, our data do show that TPEN plus DTT can effectively inhibit $\mathrm{Ca}^{2+}$ oscillations at fertilization. Previous studies have shown that loading mouse eggs with BAPTA using BAPTA-AM prevents all $\mathrm{Ca}^{2+}$ oscillations and signs of egg activation, including pronuclear formation [12]. We have used a different protocol to inhibit $\mathrm{Ca}^{2+}$ oscillations, adding BAPTA-AM after oscillations had been initiated by the sperm. Our data show that BAPTA loading of eggs is not very effective at inhibiting egg activation to the pronuclear stage if it is applied after between one and four $\mathrm{Ca}^{2+}$ spikes have occurred. This may mean that the first few $\mathrm{Ca}^{2+}$ oscillations at fertilization are able to fully activate the mouse egg. This would be consistent with the finding that application of the $\mathrm{Ca}^{2+}$ ionophore A23187, which causes a single $\mathrm{Ca}^{2+}$ increase, is able to activate mouse eggs $[7,11,15]$. However, when only one to three $\mathrm{Ca}^{2+}$ spikes have occurred in BAPTA-AM-treated eggs, or when a single large rise is induced by ionophore treatment, the extent of egg activation is often approx. 50\% [15]. In addition, the effects of both A23187 and BAPTA-AM are complicated by their inhibition of protein synthesis.

It has been shown that the combination of $\mathrm{Ca}^{2+}$-free media and A23187 is the most efficient way to activate mammalian eggs $[13,15]$. However, under these conditions A23187 is nearly as effective at inhibiting protein synthesis as is cycloheximide [25]. Protein synthesis inhibitors such as cycloheximide can activate mammalian eggs [26]. It has also been shown that protein synthesis inhibitors plus a $\mathrm{Ca}^{2+}$ stimulus can act synergistically to cause high rates of pronuclear formation in mammalian eggs [25]. It is possible that agents such as A23187 have a dual action in activating mammalian eggs. The activation of some fertilizing eggs after BAPTA-AM treatment may be due in part to an effect on protein synthesis, since we found that BAPTA-AM inhibits protein synthesis. This is consistent with finding that BAPTA loading of HeLa cells depletes $\mathrm{Ca}^{2+}$ stores and leads to an inhibition of protein synthesis [20]. Even though BAPTA-AM does not appear to lower protein synthesis to the levels seen with $10 \mu \mathrm{M}$ cycloheximide, it may still be difficult to draw a clear conclusion about the role of different numbers of $\mathrm{Ca}^{2+}$ spikes in mouse fertilization using $\mathrm{Ca}^{2+}$ chelators, such as BAPTA, if a single $\mathrm{Ca}^{2+}$ spike is accompanied by some inhibition of protein synthesis.

The effects of TPEN plus DTT on mouse egg activation contrasted with those of BAPTA, in that inhibition of $\mathrm{Ca}^{2+}$ oscillations was associated with an inhibition of pronuclear formation. We cannot rule out a possible effect of TPEN upon pronuclear formation itself, since high $(1 \mathrm{mM})$ concentrations of TPEN have been reported to inhibit the assembly of the nuclear lamina in Xenopus eggs [34]. However, our control experiments indicated that TPEN plus DTT was unable to prevent $\mathrm{Ca}^{2+}$ spikes or egg activation stimulated by electroporation pulses. These pulses are a close mimic of the pattern of $\mathrm{Ca}^{2+}$ oscillations seen at fertilization in mouse eggs [7,17]. The lack of inhibition by TPEN plus DTT on the rate or timing of the formation of pronuclei in response to such parthenogenetic stimuli suggests that events downstream of $\mathrm{Ca}^{2+}$ signalling that lead to pronuclear formation are not critical to the inhibitory effect of these agents upon fertlilization. Furthermore, since TPEN plus DTT did not significantly affect protein synthesis in fertilizing mouse eggs, the simplest explanation of why TPEN plus DTT inhibits pronuclear formation is because this combination of agents effectively inhibits $\mathrm{Ca}^{2+}$ oscillations.

Given that TPEN plus DTT inhibits pronuclear formation via an effect on $\mathrm{Ca}^{2+}$ oscillations, our data suggest that there is a relationship between the number of $\mathrm{Ca}^{2+}$ spikes that have occurred and the chances of the mouse egg undergoing activation. A greater number of $\mathrm{Ca}^{2+}$ spikes was associated with a larger proportion of eggs forming both male and female pronuclei and with a more rapid entry into the first cell cycle during development. The idea that the number of $\mathrm{Ca}^{2+}$ spikes is important for activation is evident from previous experiments in mammalian eggs. For example, with TPEN plus DTT we found that eggs undergoing only the initial $\mathrm{Ca}^{2+}$ spike at fertilization did not go on to form pronuclei. This result is similar to the finding that injecting Ins $P_{3}$ or $\mathrm{Ca}^{2+}$ solutions into mouse eggs, in order to generate a single physiological $\mathrm{Ca}^{2+}$ spike, can lead to exocytosis, but is unable to induce (or is inefficient at inducing) pronuclear formation in recently ovulated eggs $[35,36]$. Brief periods of ionophoretic injection of $\mathrm{Ca}^{2+}$, or a single electroporation pulse in the presence of $\mathrm{Ca}^{2+}$, are also inefficient in triggering pronuclear formation in recently ovulated mouse eggs $[14,17]$. In contrast, multiple electroporation pulses causing multiple $\mathrm{Ca}^{2+}$ spikes can readily activate eggs of any post-ovulatory age [16,17]. After the initial $\mathrm{Ca}^{2+}$ spike at fertilization, there appears to be a relationship between the number of spikes and the chances of the egg forming pronuclei. The occurrence of nine or more $\mathrm{Ca}^{2+}$ spikes at fertilization seems to be the minimum number associated with formation of two pronuclei, which is indicative of full egg activation. In addition, we also found that the number or frequency of $\mathrm{Ca}^{2+}$ spikes was correlated with the timing of pronuclear formation and mitosis in mouse eggs. This difference in timing did not appear to be due to a spurious effect of TPEN or DTT, since it was also seen in control, untreated eggs. These data raise the possibility that some of the variation normally seen in the timing of pronuclear formation and cell division in eggs is due to variable patterns of $\mathrm{Ca}^{2+}$ signals.

The current experiments were carried out on fertilizing mammalian eggs. The suggestion that the number of $\mathrm{Ca}^{2+}$ spikes plays some causal role in determining the rate of egg activation was made in previous studies using parthenogenetically stimulated eggs $[16,17,27]$. By using electroporation, it has been shown that the number or frequency of $\mathrm{Ca}^{2+}$ spikes can affect the proportion of eggs that form pronuclei, as well the timing of pronuclear formation [17]. The amplitude of a fixed frequency of artificially generated $\mathrm{Ca}^{2+}$ spikes can also exert a significant effect upon the timing of egg activation and of the first cell division in mouse embryos [16]. Our data suggest that some of these effects may apply to fertilization. The mouse egg may be able to respond to either the number, or the amplitude, of $\mathrm{Ca}^{2+}$ oscillations in a manner that has been suggested for many somatic cells, and recently demonstrated for the actions of isolated enzymes, such as $\mathrm{Ca}^{2+}$ /calmodulin-dependent protein phosphorylation [2,3,37].

We thank Jovita Er for technical assistance, and Dr. John Carroll and Dr. Keith Jones for comments on the manuscript proir to submission. This work was supported by the Wellcome Trust.

\section{REFERENCES}

1 Berridge, M. J. (1993) Nature (London) 361, 315-325

2 Meyer, T. and Stryer, L. (1992) Annu. Rev. Biophys. Biophys. Chem. 20, 153-174

3 Goldbeter, A., Dupont, G. and Berridge, M. J. (1990) Proc. Natl. Acad. Sci. U.S.A. 87, 1461-1465

4 Cuthbertson, K. S. R., Cobbold, P. H. and Whittingham, D. G. (1981) Nature (London) 294, 754-757

5 Cuthbertson, K. S. R. and Cobbold, P. H. (1985) Nature (London) 316, 541-542 
6 Jones, K. T., Carroll, J., Merriman, J. A., Whittingham, D. G. and Kono, T. (1995) Development 121, 3259-3266

7 Swann, K. and Ozil, J. P. (1994) Int. Rev. Cytol. 152, 183-222

8 Yanagimachi, R. (1994) in The Physiology of Reproduction, 2nd edn. (Knobil, E. and Niell, D., eds.), pp. 189-317, Raven Press, New York

9 Speksnijder, J. E., Corson, D. W., Sardet, C. and Jaffe, L. F. (1989) Dev. Biol. 135, 182-190

10 Stricker, S. A. (1996) Dev. Biol. 176, 243-263

11 Schultz, R. and Kopf, G. (1995) Curr. Top. Dev. Biol. 30, 21-61

12 Kline, D. and Kline, J. T. (1992) Dev. Biol. 149, 80-89

13 Steinhardt, R. A., Epel, D., Carroll, E. J. and Yanagimachi, R (1974) Nature (London) 252, 41-43

14 Fulton, B. P. and Whittingham, D. G. (1978) Nature (London) 273, 149-150

15 Vincent, C., Cheek, T. R. and Johnson, M. H. (1992) J. Cell Sci. 103, 389-396

16 Vitullo, A. D. and Ozil, J. P. (1992) Dev. Biol. 151, 128-136

17 Ozil, J. P. and Swann, K. (1995) J. Physiol. (London) 483, 331-346

18 Arlsan, P., Di Virgilio, F., Beltrame, M., Tsien, R. Y. and Pozzan, T. (1985) J. Biol. Chem. 260, 2719-2727

19 Snitsarev, V. A., McNulty, T. J. and Taylor, C. W. (1996) Biophys. J. 71, 1048-1056

20 Preston, S. F. and Berlin, R. D. (1992) Cell Calcium 13, 303-312

21 Quinn, P., Barros, C. and Whittingham, D. G. (1982) J. Reprod. Fertil. 66, 161-168
22 Lawrence, Y., Whitaker, M. and Swann, K. (1997) Development 124, 223-241

23 Di Virgilio, F., Steinberg, T. H. and Silverstein, S. C. (1990) Cell Calcium 11, 57-62

24 Kurebayashi, N., Harkins, A. B. and Baylor, S. M. (1993) Biophys. J. 64, 1934-1960

25 Bos-Mikich, A., Swann, K. and Whittingham, D. G. (1995) Mol. Reprod. Dev. 41, 84-90

26 Siracusa, G., Whittingham, D. G., Molinaro, M. and Vivarelli, E. (1978) J. Embryol. Exp. Morphol. 43, 157-166

27 Ozil, J. P. (1990) Development 109, 117-127

28 Cheek, T. R., McGuiness, O., Vincent, C., Moreton, R. B., Berridge, M. J. and Johnson, M. H. (1993) Development 119, 179-189

29 Salama, G., Abramson, J. J. and Pike, G. K. (1992) J. Physiol. (London) 454, 389-420

30 Hofer, A. M., Fasolato, C. and Pozzan, T. (1998) J. Cell Biol. 140, 325-334

31 Martell, A. E. and Smith, R. M. (1982) Critical Stability Constants, vol. 5, suppl. 1, Plenum Press, New York

32 Yule, D. I. and Gallacher, D. V. (1991) Cell Calcium 12, 145-151

33 Menza, M. and Michelangeli, F. (1997) Biochem. J. 325, 177-182

34 Shumaker, D. K., Vann, L. R., Goldberg, M. W., Allen, T. D. and Wilson, K. L. (1998) Cell Calcium 23, 151-164

35 Kurasawa, S., Schultz, R. M. and Kopf, G. S. (1989) Dev. Biol. 133, 295-304

36 Xu, Z., LeFervre, L., Ducibella, T. and Schultz, R. M. (1996) Dev. Biol. 180, 596-604

37 De Konick, P. and Schulman, H. (1998) Science 278, 227-230

Received 9 April 1998/20 July 1998; accepted 7 August 1998 